\title{
Making Learning Fun: Quest Atlantis, A Game Without Guns
}

\author{
$\square$ Sasha Barab \\ Michael Thomas \\ Tyler Dodge \\ Robert Carteaux \\ Hakan Tuzun
}

This article describes the Quest Atlantis (QA) project, a learning and teaching project that employs a multiuser, virtual environment to immerse children, ages 9-12, in educational tasks. QA combines strategies used in commercial gaming environments with lessons from educational research on learning and motivation. It allows users at participating elementary schools and after-school centers to travel through virtual spaces to perform educational activities, talk with other users and mentors, and build virtual personae. Our work has involved an agenda and process that may be called socially-responsive design, which involves building sociotechnical structures that engage with and potentially transform individuals and their contexts of participation. This work sits at the intersection of education, entertainment, and social commitment and suggests an expansive focus for instructional designers. The focus is on engaging classroom culture and relevant aspects of student life to inspire participation consistent with social commitments and educational goals interpreted locally.
In 1999, two high school students went on a murderous rampage at Columbine High School in Colorado, leaving 12 students and a teacher dead and wounding 23 others before taking their own lives. This atrocity triggered unprecedented media attention, with many observers blaming gratuitous violence in video games as the underlying problem, and others suggesting bad parenting, insensitive schools, and the moral decay of our times. Although many researchers have claimed that no cogent connection can be found between the use of video games and violent behavior among youth, others insist that there may be a link between video game use and deviant social behavior (Provenzo, 1991, 1992). On the other hand, some advocates of game-based learning suggest that educational video games are the only way that educators can adequately engage the "video game generation" (Katz, 2000; Prensky, 2000). The need to design educational video games represents more than an attempt to harness their tremendous motivational power: Digital multimedia provide a resource for children to develop a sense of autonomy and an awareness of consequentiality. Jenkins (cited in Laurel, 2002) suggested that children today have fewer means for expressing agency, and even fewer opportunities for engaging in play, than they have had in the past. Their physical space for exploration and play has been reduced from several square miles to an electronic screen. Squire (2002), commenting on the cultural perspective of video games, stated, 
In the United States, this fear and fascination goes back to the early 1980s, when Ronald Reagan extolled the virtues of games to create a generation of highly skilled Cold War warriors, while U.S. Surgeon General C. Everett Koop proclaimed games among the top health risks facing Americans. (p. 1)

Rather than either blindly embracing video games or impulsively brushing them aside, our work involved developing a technological innovation that lies at the intersection of education, entertainment, and a commitment to improve the world (Barab, Thomas, Dodge, Squire, \& Newell, in press; Barab et al., 2002). Our goal has been to develop a technology-rich game without guns that teaches and informs, where the excitement is about learning, growth and the development of a sense of wonder.

Over the past two years, our researchers have passed time in the same places that youths do, including carrying out an 18-month ethnographic study at a local Boys and Girls Club, visiting schools, reading teen and pop-culture magazines, and even playing video games in arcades. We began with a simple goal: Let's make learning fun. As we talked with children, parents, and others in our community, our interest expanded beyond supporting content learning and developed into a broader social commitment. To achieve these goals through deliberate steps, we had to step away from our computers, put aside our desire to design, and instead engage the ethnographic process of understanding the lives of those we wished to serve (Barab, Thomas et al., in press; Levinson, 1998). Two years into the process, our experiences and commitments have distilled into a socially responsive design that is fun and educational and that engages children in important personal, social, ethical, and environmental issues. This innovation, Quest Atlantis (QA), has been implemented at multiple sites in the United States and around the world, with hundreds of users at dozens of elementary school classrooms and two after-school sites in the United States, and multiple classrooms in Australia, Denmark, Singapore, and Malaysia. QA was released in beta form on January 15, 2003, and within less than a year, more than 3,000 participants registered and completed thousands of questsengaging curricular tasks that are connected to academic standards and our social commitments.

QA is more than a technology, or even a multiuser virtual environment. At its core the QA experience centers around an intersubjective connection or identification with the narrative of Atlantis about a world in trouble. In establishing this immersive narrative, QA leverages a 3-D multiuser environment, educational quests, unit plans, comic books, a novel, a board game, trading cards, a series of social commitments, various characters, ways of behaving, and other participant resources that collectively constitute QA. As such, QA is an example of a distributed, transmedia narrative, referring to the fact that the story line does not reside in one location or in one form of medium but is spread across various media that come together and are given meaning as the user participates in the fictional game context and investigates relevant personal issues. Participation in QA entails a personal and social engagement with the narrative, as children are asked to contribute experiences, ideas, and information to the activists of Atlantis. The mythical backstory and unfolding avenues for participation blur the boundaries between the Atlantian world and local contexts, motivating students to engage in social issues that have local relevance. The progression of quests allows students to go beyond an isolated acquaintance with these issues and with disciplinary content.

Toward documenting the effectiveness of the project, a series of studies evaluating the impact of QA on learning showed that, when responding to personal narratives, students participating in QA offered character insights that were either deeper or better supported than did students in equivalent conditions; additionally, elementary students who used QA demonstrated statistically significant learning over time in the areas of science, social studies, and sense of academic efficacy (Barab, Dodge, Jackson, \& Arici, 2003). QA has been adopted by more than four dozen teachers, distributed around the world, without any external incentive for doing so. Interviews with a subset of these teachers indicated their primary reasons to be the social commitments, direct connection to academic standards, and perception that this use of tech- 
nology would be engaging to students. Further, in addition to the thousands of quests assigned by teachers and participating staff, children ages 9-12 in both school and after-school settings have voluntarily completed hundreds of educational quests without any mandated requirement. These findings, coupled with dozens of student and teacher interviews, suggest that the QA context is engaging, meaningful, and educational.

In terms of the design of technologies for learning, the field of instructional design has successfully applied a host of systematic design models to develop numerous artifacts that have supported learning (Dick \& Cary, 1990; Heinich, Molenda, Russell, \& Smaldino, 1996; Reigeluth, 1999). Although these models are especially useful in supporting human-computer interaction designs as tested in usability studies, through our own work we have found that they may not be as effective when designing for complex, sociotechnical interactions that are mediated by technology, that evolve over time, that involve multiuser collaboration, and that are flexibly adaptive to the needs of local contexts (Barab, Schatz, \& Scheckler, in press). It is our belief that complex goals involving social interaction are inadequately met by one-time analyses or even iterative design models, and instead, require designing for sociability and designs that are flexibly adaptive to local needs (Schwartz, Lin, Brophy, \& Bransford, 1999). These types of participatory designs are iterative, distributed, and locally owned, evolving, as does a bazaar, rather than being constructed, like a cathedral.

More generally, our design work is an example of what we refer to as socially responsive design. This type of design work involves building sociotechnical structures that are explicitly designed in collaboration with, and toward the continual growth of, individuals and those communities in which they are nested. In our case this type of design work has involved balancing the educational, motivational, and social priorities that underlie our work. More specifically, our work has involved the development of QA, which includes a series of participant structures, activity sets, and social commitments that leverage a multiuser virtual environment to immerse children, ages 9-12, in educational tasks. Build- ing on strategies from online role-playing games, QA combines strategies used in the commercial gaming environment to engage users with lessons from educational research on learning and motivation. In addition to the use of entertainment strategies and research on effective pedagogy, QA is a vehicle for advancing the social agenda of empowering individuals and communities. Collectively, these three features (education, entertainment, social commitment) create an important focus for design and result in a product that is not a game yet remains engaging, is not a lesson yet fosters learning, and is not evangelical yet nurtures a social agenda. In this article, we treat our work as an example of design-based research (Brown, 1992; Collins, 1992; Edelson, 2002), describing both the ready-made environment and the complex issues that characterize its implementation in a manner that may be useful to others engaging in similar design work.

\section{THEORETICAL FRAMEWORK}

The theoretical framework for the project may be traced to the early 20th-century writings of Vygotsky (1933/1978; 1934/1986), whose pioneering work continues to inform such current theoretical discussions as activity theory (e.g., Engeström, 1987), sociocultural constructivism (e.g., Duffy \& Cunningham, 1996; Rogoff, 1990), distributed cognition (e.g., Cole \& Engeström, 1993), and situated learning (e.g., Barab \& Duffy, 2000; Lave \& Wenger, 1991). Many writers have identified central components of Vygotsky's work. Wertsch (1985), for example, described three core themes of Vygotsky's theoretical framework, including his (a) developmental model and his emphasis on (b) social processes and on the (c) mediating tools and signs. Five themes in our work are derived from Vygotsky: (a) human development, (b) social constructivism, (c) social context for thought and activity, (d) the zone of proximal development (ZPD), and (e) children's play.

While much research has focused on and discussed the first four themes, our research also reflects a less widely discussed concern of Vygotsky's, that of play. Consistent with the 
framework established above is Vygotsky's novel stance toward play: "The old adage that child's play is imagination in action must be reversed: we can say that imagination in adolescents and school children is play without action" (1933/1978, p. 93). Vygotsky's words emphasized the centrality of activity. Vygotsky wrote, for example, that "play creates a zone of proximal development for the child. In play, a child always behaves beyond his average age, above his daily behavior" (1933/1978, p. 102). It is important to clarify that for Vygotsky, play was not simply an imaginary activity somehow distinct from the real world, nor was play an unrestricted, free activity. Rather, play offers a context that is constituted by constraints of all kinds-although different and potentially liberating from many social constraints in which the child's behavior occurs. An important challenge for designers working to leverage play to support learning and the embracing of particular social commitments is to determine which constraints need to be implemented, and how these are framed so that they are useful and meaningful to the child.

\section{THE TRIADIC FOUNDATION FOR DESIGN}

A triadic foundation underlies our work. Specifically, this involves design work that forges the intersection of education, entertainment, and our social commitments. We have worked to understand how to develop a game without guns that provides excitement without violence, a girl-friendly environment that still is attractive to boys, that includes inquiry-based and experiential activities that are in alignment with standards and that can be assessed for learning gains, and that is committed to making the world a better place. Each aspect of this triad is described next.

\section{Education: Designing for Understanding}

It is generally accepted that learners should be involved in doing domain-related activities, not simply receiving the results of someone else's activities as summarized in texts or heard in lec- tures (Bransford, Brown, \& Cocking, 2002). Underlying the development of QA learning tasks, curricular units, and the experience of QA more generally, is a participatory framework that stresses hands-on action and reflection as components central to the learning process, while treating context as co-determinant of meaning. This notion of an active learner engaged in real-world activities figures centrally in the child-centered, experientially focused, and inquiry-based learning environments advocated in the literature. It also aligns with current frameworks and plans for educational reform (Bransford et al., 2002; National Research Council, 1999). Underlying the application of a participatory framework to guide the design of QA is our belief that education and actual experience bear a necessary and intimate relationship. Accordingly, our design work is grounded in three related perspectives toward learning: (a) experiential learning, (b) inquiry-based learning, and (c) portfolio assessment.

Numerous scholars and learning theorists have advocated experiential learning - the belief that learning involves real-world participation, the belief in the intimate relations between experience and education, the certainty that understandings are derived from and modified through experience, and the conviction that action and reflection are necessary features of meaningful learning (Dewey, 1938; Kolb, 1984). Regarding inquiry-based learning, there is broad consensus among educators and psychologists in a variety of fields that students learn best when the learning process involves inquiry, as opposed to the memorization of the facts and principles that were generated from someone else's inquiry (American Association for the Advancement of Science, 1993; Barab, Hay, Barnett, \& Squire, 2001; Bransford et al., 2002; Krajcik, Blumenfeld, Marx, \& Soloway, 1994; National Research Council, 1999). Lastly, in contrast with assessment as an activity distinct from the learning process, portfolio assessment involves evaluating authentic student work and proves to be particularly valuable when evaluating outcomes that result from experiential and inquirybased learning (e.g., action plans, interviews, scrapbooks, presentations, stories; Wiggins, 1992). 
Entertainment:

Designing for Engagement

Children today grow up in an exciting and changing world of communication and media. Television, digital technology, the Internet, video games, mobile phones, and personal desktop and wireless devices create novel ways for children to play, express themselves, learn, communicate, and explore texts, ideas, and identities (Willet, 2001). However, while producers of modern media and popular culture have developed profoundly entertaining products to engage our children (Jenkins, 1998; Squire, 2002), examples of materials that support academic learning remain few in number and, moreover, rarely integrated with activities in the school setting. This is particularly true with respect to video games, which have been the object of sustained critique by concerned parents and educators (Squire, 2002). A strategy commonly adopted by the entertainment industry involves developing participatory contexts that have elements of challenge, curiosity, play, and control (Cordova \& Lepper, 1996). In contrast, the education and design community has developed many curricula and contexts to support learning but has not necessarily captured the interests and motivations of children. Instead of learning from the success of modern media and pop culture producers, educators have distanced themselves from those who are the most successful in engaging children.

One of the most exciting developments in interactive electronic entertainment has been the popularization of persistent virtual worlds (often referred to as Massively Multiplayer Online Role Playing Games and multiuser virtual environments [MUVEs]). These environments grow out of the tradition of Multiuser Dungeons (MUDs), text-based environments where players collaborate to solve quests, engage in combat, develop and manage virtual businesses, organize and manage virtual societies, politick with other players, design the environment, or simply participate in text-based chats (Bartle, 2003; Kollock \& Smith, 1996). Of key importance to persistent worlds is that they are persistent social and material environments, universes with their own culture and discourses. Persis- tent worlds can be thought of as discourse communities that recruit complex cognitive and communicative practices, much the way participation in scientific communities produces complex cognitive processes (Bartle, 1996; Kollock \& Smith, 1996). Persistent virtual worlds literally support hundreds of thousands of users each day, consuming hundreds of millions of man hours per game, sporting economies that surpass the gross national product of many actual countries (Castronova, 2001; Kolbert, 2001). Since desktop computers with powerful graphics and Internet capabilities have become readily affordable by schools, MUVEs now provide an innovative medium for engaging children in learning (McLellan, 1996). For example, Bruckman (1998) has been studying how children create and share artifacts as a means of learning programming and collaborative skills in the textual MUVE MOOSE Crossing (http://www.cc. gatech.edu/elc/moose-crossing/) and in the graphical MUVE AquaMOOSE 3-D (http:/ / ww w.cc.gatech.edu/elc/aquamoose/). Bers (2001) studies how children construct identity in a MUVE (http://lcs.www.media.mit.edu/marin $\mathrm{au} /$ Zora/) through sharing stories to form a virtual therapeutic community. Dede and Ketlehut (2003) have been developing and researching River City, which uses a Multiuser Virtual Environment Experiential Simulator (MUVEES) to introduce an engaging multiuser virtual environment that teaches science concepts in a way that draws on curiosity and play (http://www .virtual.gmu.edu/muvees). How to establish a MUVE context that engages academic learning has been a focus of our work.

On a similar note, despite long-standing criticism (e.g., Cassell \& Jenkins, 1998), the software industry has been slow to respond to the needs of girls. In an exhaustive review of commercial software games, for example, Stanley (Women's Foundation of Colorado, 1999) found that "the number of software titles being produced that appeal to girls is very low, and those that are available generally lack creative content and technological sophistication, and rely largely on stereotypical themes and ideas" (p. 3); or as Herz (1997) quipped, "boys' games have the only female characters worth playing" (p. 182). Significantly, this lack of representation is one of 
a host of barriers to what critics call for as "gender equity" in computing (Turkle, Dennis et al., $2000 / 2002$, p. 264). As such, a core focus for our socially responsive design work has been to develop a MUVE that equally engages boys and girls.

\section{Social Commitments:}

Designing for Change

Some have argued that research should be grounded in social commitments that empower the disenfranchised or underrepresented to direct their own activity, rather than allow it to be directed by the agendas of others or of extant social structures. Fine (1996), for example, promoted anthropological research "which empowers as it exposes, which offers critique as it reveals not only what is not but what could be" (p. 16). Reason (1994) and Finn (1994) advocated participatory action research, referring to work that explicitly seeks to empower both groups and individuals. Delgado-Gaitan and Trueba (1991) developed a framework called the Ethnography of Empowerment, which seeks to uncover disempowering structures, leading to the eventual empowerment of disenfranchised communities. Levinson (1998), in support of bringing an empowering social commitment to research, wrote, "The justification for [applied] research does not derive solely from theoretical considerations; it derives from a perceived problem in need of solution, or an opportunity for humane intervention" (p. 86).

It is our view that not only education but even design work should be conducted in a socially responsive manner; that is, aspiring toward such ideals as empowerment, and being socially responsive while articulating and even operationalizing those commitments. Firmly ensconced in our research, design, implementation, and evaluation practices, then, this central theme of social empowerment infuses our work with meaning.

Applied or "critical" ethnographers are committed to exposing unequal power structures and advocating the social consequences of anthropological work (Freire, 1970/2000; Levinson, 1998). This work takes a step toward bringing a transformative agenda to the more value-neutral, traditional ethnographic or anthropological approach. The goal in this work is to uncover, expose, and deconstruct those power structures that serve to subjugate a segment of a population (Glesne, 1999). Said simply, critical ethnography seeks to empower the people it aims to understand. However, Barab et al. (2002) argued,

While critical ethnography does embrace a social commitment or "critique" and, as such, has value added over traditional ethnographic accounts, it does not necessarily package this critique in a manner that can be used by others who were not part of the site in which the critique was developed, thereby limiting its potential impact. (p. 2)

The field of instructional design has produced many products, and has developed numerous principles for designing them. While these well-designed programs, software applications, and online communities have supported deep understandings and novel practices, less common in this design work is an agenda that has the goal of exposing and transforming inequities. It is in the service of an altruistic agenda that we have taken up socially responsive design, which has at its core the goal of designing sociotechnical structures that support users and those communities in which they are nested in their own transformation.

\section{METHODS}

Our design process for this project can be thought of as an example of design-based research, or what Brown and Collins referred to as design experiments. This methodological paradigm was introduced by Collins (1992) and Brown (1992), who advocated a new methodological approach for carrying out research and design work in the context of real-life settings. In communicating the activity and the need, Brown (1992) stated,

As a design scientist in my field, I attempt to engineer innovative educational environments and simultaneously conduct experimental studies of those innovations. This involves orchestrating all aspects of a period of daily life in classrooms, a research activity for which I was not trained. (p. 141) 
Design-based research involves introducing innovations into the booming, buzzing confusion of real-world practice (as opposed to constrained laboratory contexts), and examining the impact of those designs on the learning process (Barab \& Squire, 2004). Lessons learned are then cycled back into the next iteration of the design innovation. Roth (1998) found that:

Because of the closeness to the classroom, design experiments constitute research efforts that are not only suitable to generate theory from practice, butbecause of the thick descriptions they can provideinform practice and practitioners in meaningful ways. (p. xvii)

Because design experiments develop theory in practice, they can lead to interventions that are trustworthy, credible, transferable, and ecologically valid.

Socially responsive design work adds another layer of complexity to the already complex process of instructional design. One no longer simply designs an artifact to deliver predefined content or to support a process in which the final product is already known. Instead, socially responsive design work involves engaging participants in activities that expose inequities, stirring interest in complicated issues and stimulating local ownership over the entire process. Socially responsive design work brings together critical ethnography, instructional design, and social activism with a focus on producing a designed artifact and process that has at its core the goal of facilitating individual and societal transformation (Grills, 1998), creating ties to action research (Eden \& Huxham, 1996; McNiff, 1995; Stringer, 1996; Wells, 1999) and critical ethnography (Freire, 1970/2000; Levinson, 1998). However, where the action researcher and the critical ethnographer stop at the daunting task of supporting change in one particular context, the design ethnographer accepts the added challenge of reifying this critique and associated social commitments into a design that can be taken up and usefully integrated into other contexts.

Given the above complexities, socially responsive design involves the process of design ethnography (see Barab, Thomas et al., in press). As a brief overview, design ethnography involves four components: (a) developing a "thick description" of one context (Geertz, 1976), (b) developing a series of social commitments that have local and global significance, (c) reifying these understandings and commitments into a design, and (d) supporting scaling up and local customization. This process involves design work coupled with the continual production of naturalistic interpretations based on both qualitative and quantitative data over extended time frames and at multiple sites; it involves using multiple data sources and continually cycling between the processes of data collection, coding, and analysis, with the lessons learned at each step being used to direct the subsequent processes (Scriven, 1983; Stake, 1978, 1995). Qualitative data collection efforts target the evolving technical structures (e.g., Websites, developed artifacts at the Centers, design decisions) as well as the social relationships, interactions, memberproduced work, and conver- sations (online and face-to-face) through which these structures are informed and take on meaning. Further, in this work the technical structures and personal relationships are not treated separately, but instead ethnographic procedures and specifically, participant observation, interviews, and member checking are used to better understand the social issues as they relate to the technical affordances of project elements.

The interpretations presented here are derived largely from the qualitative data, collected by 10 researchers over a 30 -month period from multiple locations both here in the United States and overseas. Our understanding of the data began through our reflecting on our experiences and the extant data to produce a list of the issues that were important for understanding QA. However, rather than existing as episodes or periods independently of each other, these issues may be considered as braids that, when described as a collective, form the tapestry that is QA. Although it is common to look to the designed (technical) artifacts as QA, a richer and more useful perspective can be gleaned from an appreciation of the complex sociotechnical issues that have surrounded the development and implementation of QA. In identifying which issues to highlight, we examined our field notes and submitted articles; reviewed e-mail 
exchanges, student work, and interviews; and reflected on our first-hand experiences to develop a useful list of those braids that were most significant to the project and that would be most useful to others. This process resulted in the identification of four braids presented in the Core Themes section of the results, following the discussion of the flexibly adaptive design itself: (a) Creating a Vision, (b) the Participatory Design Process, (c) Developing a Metacontext, and (d) Supporting Project Implementation. To provide a context for the reader, described first is the technical design, with the caveat that this is a fragmented picture of the larger sociotechnical design that constitutes QA.

\section{FLEXIBLY ADAPTIVE DESIGN: THE} TECHNICAL INSTANTIATION OF QA

A central component of role-playing games is that the user assumes a role within the game context. In QA, the child is assigned the task of using the virtual environment and responding to the associated quests (developmentally appropriate activities that include a task description, specific goals, and useful resources), so as to help the Council of Atlantis restore lost wisdom. The QA story line (or myth), associated structures, and policies constitute what is referred to as a metagame in the commercial gaming sector. A metagame refers to a genre of play in which there is an overall structure that lends form, meaning, and cohesion to collection of nested activities or games, all of which have their own identifiable rules and challenges. This structure creates a boundary condition that unites the individual actions and outcomes of these otherwise disparate activities. Specifically, the QA metagame consists of several key elements:

- A shared mythological context that establishes and supports QA activities.

- A set of online spaces through which children, mentors (local staff, older children, or teachers), and Atlantian characters can interact with each other.

- A well-defined advancement system centered on pedagogically valid activities that encourage academic and social learning.
- Regalia and rewards associated with advancement and wisdom.

- An individual home page for each child, showing their advancement and serving as a repository for their work.

Through this metacontext, quests and member behaviors are targeted and instilled with meaning, with their primary function being both structural (providing a cohesive framework) and motivational (providing an engaging context to stimulate participation and learning). However, in contrast to traditional role-playing games, in QA the student's game identity and activity are dependent on his or her ability to exit the virtual environment to accomplish quests in the physical world. Given the authentic nature of participation, identity within QA might best be considered an extension of one's daily self, rather than a fiction, experiment, or substitute. At one level, QA is a MUVE that immerses children in educational tasks as part of an online adventure to save Atlantis from impending disaster. However, the QA project is more than a computer program; QA is best viewed as a series of participant structures, activity sets, and social commitments that constitute the QA identity-what is referred to in the business world as a brand.

The QA community consists of both the virtual space and the face-to-face QA Centers. In order to participate in QA, children must be associated with a particular QA Center (such as participating elementary schools, Boys and Girls Clubs, local libraries) and must register on the QA Website. Once students are registered, they may use the QA software at any participating Center or from other locations with Internet access. When the QA software first opens, students are presented with a split screen in the interface window: On the left is the virtual environment through which students can explore, interact with others, and find quests; on the right is a side-bar browser, opening dynamically generated Web pages to support the QA experience (see Figure 1).

The virtual space is organized into different 3-D worlds; by using their avatars students move through these worlds, meet the avatars of other students, participate in communal activities, and explore different quests. The partici- 
Figure $1 \square$ A screenshot from Quest Atlantis, showing a scene from a village on the left and the homepage for a student on the right.

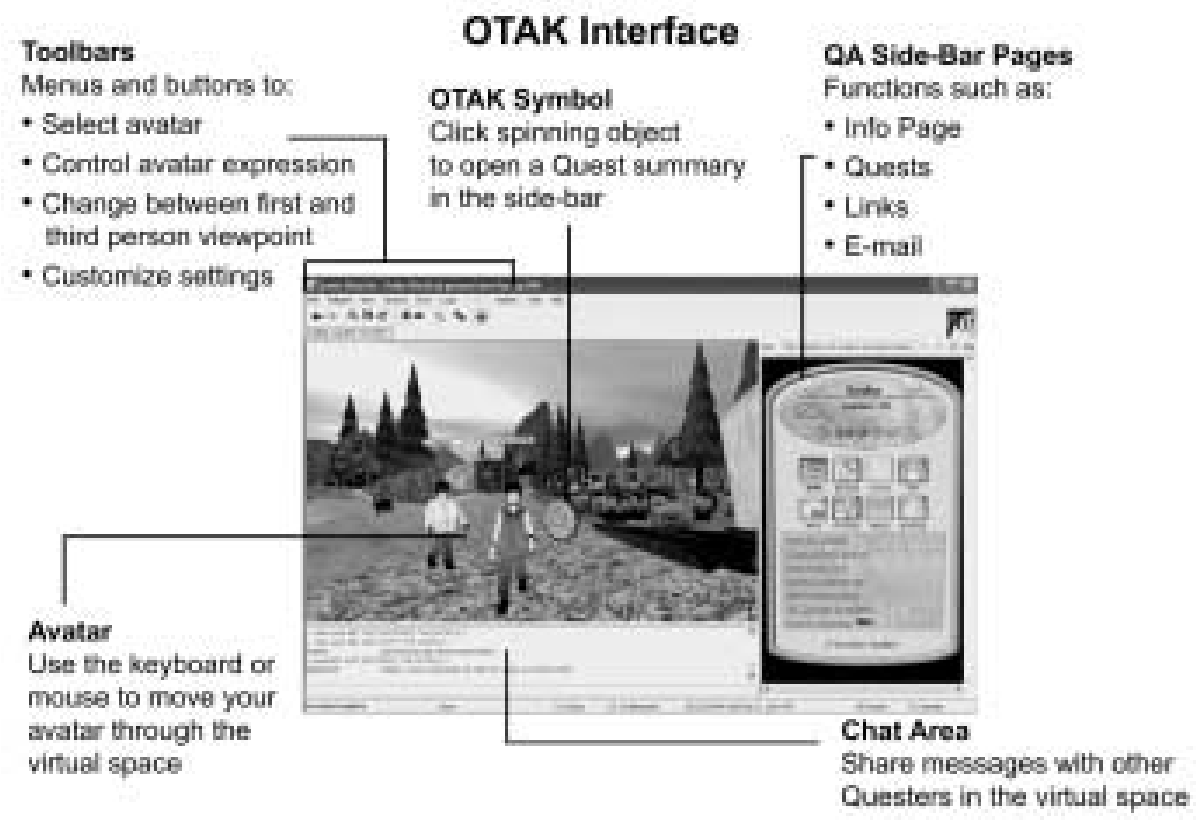

pant's attributes persist from one session to the next and are saved within an avatar, that is, a virtual placeholder symbolizing one's identity in the virtual space and allowing interaction with the environment (Damar, 1998; Poole, 2000). The avatar itself is the vehicle through which the participant interacts with the environment; the avatar develops a customized look, a status, and a character as it interacts with the avatars of other members, allowing the individual to experiment with different aspects of his or her identity (Bruckman, 1998; Donath, 1999; Turkle, 1994). The interface features toolbar options for customizing the experience, along with a function for text-based chatting. The virtual world presents links that open quest pages and other QA pages in the side-bar.

The pages that open on the right side of the QA interface perform different functions, but they behave in a similar manner: They all present summary information in the side-bar, and this information can be opened in a larger popup window for viewing and editing (see Figure 2 for the most common features of the side-bar). The side-bar pages host custom home pages, introduce quests, announce timely news, and serve other functions. These pages are opened when the user clicks "hot" objects in the virtual 3 -D space. The 3-D space also includes other structures that facilitate novice and expert use, allow students to experience rudimentary 3-D building, facilitate collaboration among members, and offer a multitude of other activities that support identification with the QA experience and that help to actualize our social commitments and support learning. Children can even coquest with each other, completing the same quest tasks together and then individually uploading their reflections.

Other QA activities extend beyond the virtual space: For example, students develop and submit their work on quests, and they communicate with each other and with the Atlantis Council. The pages in the side-bar also support these activities by offering information on each student's work, providing tools for sending email within QA, and giving each student a custom home page that other students can visit. The home page is the default page in the side-bar, and the other pages are opened by clicking the navigation links. There is also a Teacher Toolkit that teachers can use to register students in their 
classroom, register quests for their particular classroom, review student work, assign student work to other students for review, assign awards to individual students, and keep track of student e-mails and chat entries.

By moving their avatar through the on-screen environment, citizens travel to virtual worlds where they can read about and listen to the themes of these worlds, complete quests, talk with other children and with mentors, and build their virtual personae. The virtual spaceOTAK - is divided into worlds. Each of the four primary worlds of the OTAK-(a) Unity World, (b) Culture World, (c) Ecology World, and (d) Healthy World-is divided into three villages (e.g., Unity World includes Global Village, Community Power Village, and All About Us Village) that hold up to 25 quests. The OTAK currently contains the OTAK-Hub, and the four primary worlds. The OTAK-Hub is the central location from which to teleport to each of the worlds. It also offers introductory quests, the Trading Post, general information, and the Quests of the Moth. Each village has a title reflecting a theme-for example, Community Power, Animal Habitats, Water Quality, Words of Meaning - and an associated series of engaging quests. The themes were designed to span diverse areas of knowledge and feature something for almost everyone, yet still overlap academic categories. Each village houses a spectrum of quests (engaging academic tasks that take 20 min-1 week to complete) ranging from simulation to application problems of varying levels of complexity.

Completing quests requires that students participate in real-world, socially and academically meaningful activities, such as conducting environmental field studies, interviewing families and friends, researching community problems, examining current events from multiple perspectives, writing autobiographical anecdotes, producing advocacy media, or developing real-world action plans. Each quest is also connected to local academic standards and to at least one of our social commitments, discussed below. Students can select a number of these quests, based on their interests or as assigned by their teacher if they are participating as part of a school. The children's work on quests, which is submitted through an interface integrated with the client software, includes both content-area

Figure $2 \square \quad \square$ The OTAK side-bar, which introduces quests, announces timely news, opens the Trading Post, and serves other functions.

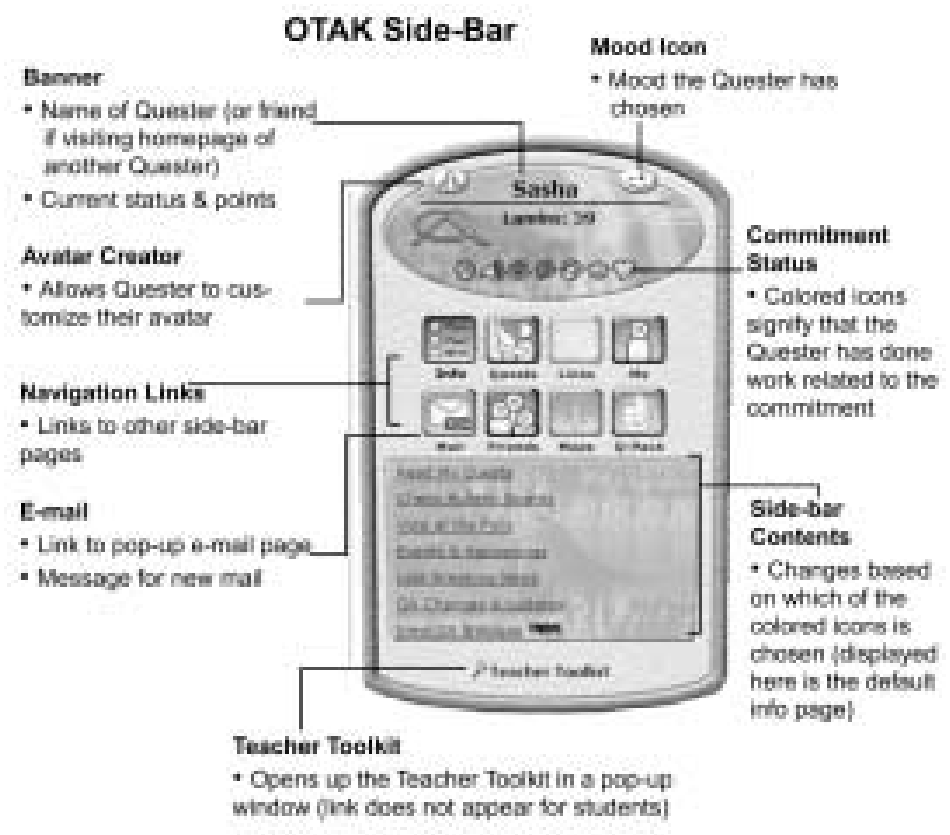


findings and personal reflections to foster retention, critical thinking, and metacognition. Both the content-based findings and the personal, process-oriented reflections are assessed by the teacher and/or other students. In this way, the quests bring together two traditionally disparate forces - the motivation of free play and the rigor of academics-and, through a system of checks and balances, they scaffold children's exploration while ensuring robust content.

By completing quests, the child earns points and gains status in the virtual environment. These points can be exchanged at the Trading Post for items such as QA stationery, stickers and pins, and even trading cards about famous people- the latter became a powerful form of motivation in our initial work. Over time and after completing a series of quests, the student can gain virtual world privileges, such as walking through objects and flying, and even acquire building permission for the virtual space. Additionally, student home pages allow students to develop an online persona, itself a powerful motivator for engaging participation in online worlds (Turkle, 1995), and moreover, these personae contribute to formative identities or sense of self (Bers, 2001).

Children's work on quests includes responses (text reports or uploaded file attachments) and reflections (text commentary), both of which are submitted through an online system that connects students and the Council. As part of the legend underlying QA, this Council is a group of Atlantians committed to staving off disaster by learning about the Earth by way of children. Council members are characters that appear in such media as the QA videos, comic book, and novella, as well as the 3-D space and the introductory video for commencing the project at new sites. Although children know the Council is not real, they, along with participating teachers, consistently state that they find the story line quite engaging, and helping the Council rebuild the lost knowledge of Atlantis serves to establish an altruistic context for participation.

An additional component that supports implementation is the QA project unit plans. The two-to-three-week-long units aid the teacher by providing a manageable implementa- tion structure or activity set, which includes various quests and a culminating activity, such as children developing a "world's fair" to promote international awareness. Another example is the diversity unit, in which children produce a diversity affirmation book; that is, a collection of child-developed poems, stories, songs, pictures, artwork, and such; along with a diversity play, in which students engage community issues as part of a script performed at the local theater for parents and community members. The important point is that with currently more than 400 quests, 8 unit plans, and 25 starter activities, no teacher could possibly implement all QA activities. Therefore, when conducting workshops with teachers, we introduce QA as a collection of resources, opportunities, social commitments, and an engaging MUVE structure that they can integrate in diverse ways to meet local implementation needs-a process described in the next section.

\section{CORE THEMES}

\section{Creating a Vision}

An important feature of effective design work is that it is grounded in the life worlds of those it is meant to serve. Most instructional designers usually begin with some sort of needs or context analysis (Heinich et al., 1996), to understand the potential context of use. Though we did collaborate with local sites to conduct some limited context analyses, in the beginning we believed that we had a fairly solid vision of what needed to be designed and so treated these sites more as usability sites than as precipitants of a fundamentally altered vision (Barab, Thomas et al., in press). Over time, however, these sites became less of a repository for our predesigned vision and more of a collaborative group with whom to coconstruct a vision of QA. Toward this end, we spent more and more time listening, eventually choosing to build an ethnographic account of one after-school site (Geertz, 1976), and conducting interviews and focus groups with others, all of which were used to guide our future design work. This process uncovered much detail about the various life worlds of the groups with whom we designed QA. 
This attitude of treating potential and actual participants of the system as collaborators has permeated our thinking, and, two years later, continues to inform the project through its scaling and adaptation. Another core change in our thinking during this initial period involved shifting from designing a learning environment simply for content learning, to developing a series of participant structures targeted toward the development of the entire child. This shift reframed QA less as a Website or computer program and more as a sociotechnical network constituted by various design structures, numerous participants, emerging and ongoing social relationships, and particular norms and values. Moreover, the commitment to socially responsive design became more evident: For instance, instead of simply supporting math and science learning, quests were focused on the adopted social commitments. This also led to the development of Unity World, for example, with its associated villages of Community Power, Global Awareness, and All About Us-titles reflecting a commitment to empower the whole learner and his or her nested communities.

Toward understanding the lives of those with whom we design, we spent time learning about the television shows children liked to watch, the movies that interested them, the music they listened to, the magazines they read, the games they liked to play, and what and who were considered "cool." The children told us what they liked to do in school, at home, and with friends, and they let us work with them in the computer lab at the after-school center. The children also borrowed cameras, photographing scenes in their lives to show us what was important to them. With this data, we attempted to identify patterns, such as which games the girls liked to play and which most interested the boys, and, as much as possible, worked to instantiate all of these interests into the developing project. As the design of particular structures progressed, our use of rapid visual prototyping helped us to understand and respond to the preferences of the children.

The evolving mission of QA is to support children in developing their own sense of purpose as individuals, as members of their communities, and as knowledgeable citizens of the world. Toward realizing this mission, the program came to embrace seven social commitments and respective, abbreviated slogans that underlie our design decisions:

1. Creative Expression-I Express Myself.

2. Diversity Affirmation-Everyone Matters.

3. Personal Agency-I Have Voice.

4. Social Responsibility-We Can Make a Difference.

5. Environmental Awareness-Think Globally, Act Locally.

6. Healthy Communities-Live, Love, Grow.

7. Compassionate Wisdom-Be Kind.

These commitments are evident in the animated movies, emergent plotlines, choices of topics for quests and unit plans, and posters adorning Center walls. They are what drives our work and what excites the teachers to become involved. In fact, teachers remark that the most common reason they join QA is to be involved in a project that is connected to standards, that integrates technology, and that has meaningful social commitments.

A final aspect of the initial vision relates to good pedagogy, specifically, the commitment to support experiential and inquiry-based learning, as well as to integrate portfolio-based assessment practices. The design of QA reflects the need for both action and reflection, with a focus on inquiry-based activities that support the learner in generating information, in evaluating its relevance to real-world problems, in constructing meanings in authentic settings, and in justifying the credibility of assertions. This is demonstrated best by the quests, which introduce a problem for inquiry and provide resources to support learners in their inquiry. These inquiry-based activities are grounded in real-world issues and require the application of principles, methods, and conceptual understandings associated with core disciplines.

\section{The Participatory Design Process}

Consistent with others involved in participatory design work (Gaver, 1996; Schuler \& Namioka, 1993; Schwen, Godrum, \& Dorsey, 1993; Was- 
son, 2000), our design process has involved a collaborative posture in which those who implement the design work also have a hand in its evolution. This began at our initial Boys and Girls Club site and has continued throughout the implementation and scaling process. These collaborations provide opportunities for us to collectively develop understandings on how to integrate QA in particular contexts and, at the same time, to understand how to reconfigure QA to better support multiple contexts. Rather than distribute a completed design, our maintaining a participatory posture creates a better relationship with future Centers and helps us to learn through these collaborations. It also allows the Centers the freedom to implement QA in a manner that meets their local needs. Throughout the design and implementation process, we have worked with children, staff, and parents as codesigners, mutually determining the purpose, value, and worth of the emergent collaboration and design work. For instance, as participants implemented QA in their respective contexts, they sent us dozens of e-mails on an ongoing basis offering suggestions that were then used to direct further design revisions. The agendas of our collaborators have been as significant in determining the direction of our research and development as were those goals that initially informed the project.

A core challenge of design work is to avoid becoming more focused on the designed product than on the people and interactions that the design was developed to support. Even when design work aims to support human-computer interactions, there is a commitment to usability studies in which the designer observes the use of the final design in context by potential users. However, our focus is not simply to design usable technical structures that support humancomputer interactions, but to develop technical structures that support human-human interactions as mediated through technology. Designing in response to the social transactions and emergent norms for use is complex work that involves addressing both usability and sociability challenges (Barab, MaKinster, Moore, Cunningham, \& the ILF Design Team, 2001; Preece, 2000). When designers focus on ongoing sociability issues, they have the opportunity to facilitate social interactions that are supportive of the program and the user, as well as the community of which they are a part.

Although participatory and emergent by design, the QA program must articulate a set of easily understood goals that support meaningful learning. Balancing entertainment and education has been a delicate and difficult task, one that directly speaks to the nature of both motivation and cognition. In terms of the former, the entertainment value (as an expression of motivation intrinsic to the game) is incredibly important toward establishing a context for learning that will also be of interest to the children. However, pandering to too many requests for entertaining products puts us at risk of becoming educational researchers who simply support the use of video games in education. The balance of play and learning is a delicate one, and at the center of this balance is that the quests-the chief form of achievement and cause of advancement-require academic work. In terms of engagement, we have found that the social commitments are frequently as motivating to children as are the entertainment aspects of the project.

With respect to balancing the educational and entertainment value of QA, when children are introduced to QA as a game, they may be disappointed and frustrated by the amount of academic work required. However, when children are told that they are going to do educational activities on the computer, then they themselves characterize QA as a game and become more willing to do the work. In fact, one child involved in the program in an after-school context referred to QA as a work activity, but when QA was introduced at his school, he described it as a game. Such a shifting characterization of the program not only reveals our triadic foundation as dynamic but emphasizes the role of context in codetermining meanings. Our recent research involved interviewing four dozen children and collecting questionnaire data from another 200 about how they rank QA in terms of playing, helping, learning, and working. While some activities might have scored high on one particular dimension, QA scored significantly higher on the sum of all four dimensions than any other activity in which the 
students engaged (e.g., non-QA school work, playing with friends, reading books, etc.) (Barab et al., 2003). The fact that children regard QA as a form of play even though they are doing school work, and that they rate it almost as highly on this dimension as playing video games, is particularly interesting, given that a significant amount of QA activity involves doing academic work. Interviews with children suggest that the metagame context can turn even an academic activity into one that is more associated with play-a point taken up in the next section.

\section{Developing a Metacontext}

A core component of role-playing games is that the user assumes a role within the game context. As stated above, a metagame refers to a macrolevel structure that subsumes and gives coherence to multiple microlevel activities. This is frequently the case in online role-playing games such as Everquest (http://www.everquest.com) or Asheron's Call (http://www.asher onscall.com) (Axelsson \& Regan, 2002; Koster, 2000). In these games, there is some larger task (e.g., saving the world from invading monsters) involving multiple activities such as killing monsters, building houses, purchasing armor, finding gems, accruing apprentices, and so forth. In QA, members are asked to help the Council rebuild the Arch of Wisdom, which was destroyed by misguided rulers seeking technological progress at any cost; as a result, their world faces environmental, moral, and social decay. Through completing quests, developed primarily by the fictitious Atlantian Council to address specific social issues, students assist the Council in building a collective knowledge base to help them address their problems and save Atlantis from problems similar to those faced on Earth. To the extent that students "buy in" to this story line, they complete quests for the game, but at the same time address real-world issues on Earth.

In terms of entertainment, a large part of the success of persistent virtual environments involving role playing results from their providing users the opportunity to enter a different (virtual) world (Reid, 1999). A key aspect of QA is that the development of the game identity reflects the child's ability to accomplish activities in the real world, not simply in the virtual environment-bringing together what is real and what is virtual. In this way, the fantasy overlaps with the real world, providing a mutable platform through which our social commitments become manifest and suggesting that the QA context is not simply a role-playing environment, but extends through a story line that directly engages issues of real-world identity and community. Neither the entertainment nor the educational aspects of QA are given priority: Favoring the latter will alienate the children, while favoring the former will alienate those stakeholders (teachers and staff) who are the gatekeepers of the school.

The design for QA has involved establishing structures in which learning and reflection are central, even becoming activities that are meaningful in their own right. Providing evidence of this occurring is that, in addition to the thousands of assigned quests, children have completed hundreds of quests either in after-school contexts or without being assigned by their teachers. Further, in one branch of our research, students complete one of the quests either as part of the QA context or, alternatively, as a worksheet stripped of any mention of the Council or the QA context more generally. Preliminary results show that students are willing to complete significantly more work and rate the activity as more interesting when completed in the context of QA (Barab et al., 2003). Even so, the use of point systems and various rewards structures to motivate student work may be considered coercive, so we continue to seek to establish ways to focus student participation, not solely on earning points, but instead on the quality and pleasure of the work itself. Still, despite this concern over the use of points and associated reward structures to engender participation, the evidence does not suggest that these structures undermine other school work.

Consistent with traditional conceptions of multiculturalism, the QA Council includes male and female characters having features associated with African American, Asian, Hispanic, and Anglo populations. Though this distribution is grounded in the demographics of the 
early student participants, further reflection might challenge whether mere balanced heterogeneity truly represents broad cultural diversity. In fact, our Australian and Singaporean collaborators have commented that the story lines, norms, quests, and ways of interacting within the program may not represent those associated with people from their own countries. Accordingly, this led to the development of multicultural quests and the featuring of issues of cultural homogeneity within the QA legend, with the Council positing the lack of multiple perspectives as a core problem facing Atlantis. In this way, issues of multiculturalism are implicitly engaged through the QA backstory, and explicitly targeted in particular quests.

Entwined in the history of QA and the development of its structures is our ongoing concern with gender representation (see Cassell \& Jenkins, 1998), including responding to suggestions from industry (e.g., Laurel, 2001) and our own research. For example, the bright and vivid colors of the virtual worlds, as opposed to the dark and gloomy look of many MUVEs designed by the entertainment industry, were implemented in particular to engage girls. Girls express enjoying plot and story, and we supported this with a rich backstory for our legend, and worked to develop the characters, including featuring a blue-haired teenage girl as the central character, an identifiable entry point for girls into the project. In fact, we have consistently learned through interviews with children and teachers that choosing a girl as the central character has been one of the main reasons that initially girls find QA to be engaging. Therefore, we consistently ensure that in each movie poster, comic, novel, and so forth, we always have a girl featured. Of the more than 3,000 registered questers, $49 \%$ are female, and these girls have submitted more than half of the quests, and have sent more than 15,000 e-mails (58\%), while boys have sent only 11,000 (42\%); the girls have posted more than 85,000 lines of chat $(55 \%)$, compared to the boys, who total 70,000 (45\%). Additionally, girls have rented as many plots of land and built as elaborate virtual structures as have boys.

Similarly, many boys reported that they collected trading cards of all kinds: They like col- lecting them, talking about them, and trading them. For this reason, QA trading cards were developed with the expectation that as students earned points through questing, they could trade them in for cards. Our trading cards represent real people (e.g., Jacques Cousteau, Mahatma Ghandi, Mother Theresa) and their positive contributions to the world. Significantly, students engage in quests, not only for school credit or QA points, but as part of the greater mission in helping the Council of Atlantis rebuild its lost knowledge, an altruistic context that has proven quite compelling to girls and boys alike.

\section{Supporting Project Implementation}

A commonly cited feature of successfully implemented educational programs is their ability to adapt to the needs of local contexts (Fullan, 1993), particularly with programs that entail a reform agenda such as supporting educational innovation, identity transformation, or cultural change. Every context challenges the project with a new set of circumstances, personalities, resources, cultural norms, and other variables that directly and indirectly speak to the viability of project implementation. Many researchers who have studied the implementation of projects in multiple settings have found that local customizability is the key to successful implementation (Randi \& Corno, 1997). That is, the program must be flexible enough to adapt to local conditions and provide meaningful ways for local stakeholders to legitimately feel that they are part of the project and that their opinions are not only respected but show tangible manifestations in their local iteration of the project. However, this customization can go too far if the local adaptations result in a metamorphosis that renders the innovation unrecognizable. For example, early on in the project, a large and promising district proposed simply using the technological skeleton yet not adopting the particular curriculum or social commitments. Despite our enthusiasm about their interest and the funds they would bring to the collaboration, our conviction was that their proposal disregarded the most innovative and important 
aspects of QA. On the other hand, to the extent that our social commitments may be reified in the design, a user's engagement with the design artifacts may afford and even invite consideration of the commitments, so in this regard a robust design might help even philosophical orientations survive in contexts hostile to them.

Schwartz et al. (1999) argued for flexibly adaptive design processes that allow educational products to be designed in a way that strikes a balance between complete control by designers and easy reconfiguration by teachers and other stakeholders who will use the products. Offered as components of the QA program are a variety of resources in various media (i.e., a MUVE context, comic books, a novel, a board game, trading cards, unit plans, scavenger hunts, quests), so that teachers can integrate QA based on their own local needs. In fact, there is no one distinct QA program: Multiple activity sets afford the production of different activity systems supporting different needs. For example, a situation in which a teacher implements only random quests or only tangentially engages the QA story line results in the creation of a context very different from one in which a teacher implements a complex unit plan. Even in terms of unit plans, some teachers focus on language arts, others on science, and still others on social studies, for example. Having multiple participant structures allows us to support the needs of different contexts as well as different teachers, teaching styles, and preferences, and also different students, parental concerns, and stakeholders. One problem with this freedom arises when teachers omit aspects deemed central to our pedagogical and social commitments. For example, one teacher who used QA with five different classes never showed students the legend, thus undermining the social commitment and the "gameness" of QA. Another teacher, instead of providing rich portfolio feedback, assigned numbers from a rubric score as review feedback for student quest responses. In both of these circumstances, important aspects of QA were compromised. However, all of these relationships begin with a discussion of the triadic foundation of our work so that teachers understand our pedagogical framework, our social commitments, and the metagame structure.
The tension between reproducing innovations in multiple contexts our of whole cloth and offering a program that flexibly adapts to multiple contexts is central to the problem of broad diffusion. How does an educational program maintain its fidelity while adapting to different contexts? At what point do these adaptations to local contexts become lethal mutations (Brown, 1992) that kill, dilute, or distort the flexibly adaptive innovation? A major struggle in the implementation of QA has been to usefully harness this tension between the need for local customization and maintaining the program's integrity, finding the strengths in both without endangering either. This tension is apparent in the inquiry-based pedagogy that underlies much of QA. A common initial sentiment of teachers when they hear that QA is a technological program to support learning is that QA will somehow teach children. However, QA does not teach, but instead provides an engaging context and set of nested activities, all of which require active participation on the part of the student and teacher. As a result, implementing QA actually means more work for teachers, as they are required to support students undertaking quests, and then review student work-all of which occurs in a public space that can be scrutinized by the school administration and even the parents of the child who submitted the work. Teachers, and certainly staff working at afterschool sites, may not be trained to support inquiry-based learning, thus creating scaling challenges as teachers and staff must master a new technology, understand the framework of QA, and employ a new pedagogy that is time consuming and less expedient than simply having students learn specific facts.

A final approach undertaken to support scaling involves the use of "buoys." A buoy is an individual who has become a committed "early adopter" (Rogers, 1995) of the program. The buoy, who must be a person from the local context and not simply a QA staff member, assists in the program's technological, pedagogical, and social implementation by serving as a mediator between those at the local site who are implementing QA, and the QA staff. To support QA both nationally and in international contexts, local educators were identified to serve as buoys 
to support the program and its local implementation. Currently the QA project has buoys in Florida, Australia, Singapore, Denmark, and Malaysia, with more than 3,000 registered users. These buoys use QA not only as a program to support the educational and social needs of children and their communities in each local setting but also as research sites. For example, our colleague in Australia is supporting teachers by helping them register students and integrate unit plans, yet at the same time she is collecting data to publish as her own research and to inform our project evolution. In this way, each QA site becomes a site of research, with the buoy serving as the chief architect of that research. The buoy is thus a codesigner of QA, an implementer of the program, a researcher of its implementation, and an evaluator. The findings that spring from this research and evaluation are cycled back into the design of QA to inform its continual redesign and ongoing development. This collaborative partnership supports the scaling of QA as it continues to be implemented in an increasing number of sites and range of contexts.

\section{DISCUSSION}

This description of QA has provided an overview of both the ready-made structures and the core themes that characterize its design and implementation. At its core, QA sits at the intersection of education, entertainment, and our social commitments, creating many tensions as we work to balance these features to produce a metagame without guns that supports academic learning, individual development, and social transformation. In this manner, the project integrates principles underlying the development of entertaining games (play, challenge, curiosity, and control) into the design of a learning environment, a practice frequently absent from textbooks and school-based activities. The project also entails a rich metagame context through which children perceive their participation as meaningful and engaging. More generally, the QA project may be regarded as one instance of socially responsive design work, a process that involves developing sociotechnical structures that have an altruistic agenda and engaging participants in their own and their communities' ongoing transformation.

Central to socially responsive design work is a methodological approach referred to above as design ethnography. Whereas the basic ethnographer builds a thick description with the goal of understanding the culture (Geertz, 1976), the critical ethnographer (Levinson, 1998) goes a step further to leverage this understanding to develop a critique with the goal of transforming the context that is being researched. In our work we have gone farther still, reifying this critique into a design (consisting of artifact and process), with the expectation that this design will engage children and their communities at others sites in meaningful issues affecting their local communities. This latter process risks the charge of ethnocentrism; however, our conviction is that if the process is managed with respect, if the design itself is flexibly adaptive, and if each implementation is treated as collaborative, then this type of design work bears much potential to positively influence the world. At a basic level, we have come to value the importance of having a flexibly adaptive program (Barab, Thomas et al., in press). The term flexibly adaptive can be related to the diffusion of innovations such as QA by considering that innovations must be able to adapt to multiple contexts if they will be broadly implemented.

As an instance of socially responsive design work, QA combines elements of playing, working, and helping. It is our conviction that if we as educators do not develop more gaming-like principles into our design tool kits, then the entertainment industry and market, which have less vested interest in supporting positive identity development than we do, will be the teachers of our children. We have tried to capture the enthusiasm and motivation inherent in entertainment products, yet situate these into a positive context focused on empowering children, supporting learning, and promoting a social agenda. This has involved more than simply designing a product, but has involved the creation of a QA brand, including the development of sets of resources that include but go beyond the computer program. In this way it is our challenge, much as it is for "Sesame Street" or 
"Blues Clues," to develop a vision for what it means to be a product user and then to embed this vision as a potential outcome of interacting with the numerous project resources. However, it is not simply our goal to ascribe usage or particular values to project participants, but to develop resources that support local interpretations of the core commitments, values, and beliefs that underlie our work. Further, it is our expectation that the lessons learned in QA will extend to activities outside of QA as well.

QA has a number of characteristics that have helped it become a valuable intervention for schools. First, it advances a social commitment. The mission of QA is to support children in developing their own sense of purpose as individuals, as members of their communities, and as knowledgeable citizens of the world, with each quest targeting at least one of the dimensions of development that we hope to foster. Second is its connections to standards. From its inception, and through the support and participation of teachers and administrators, QA activities have been academically grounded, including connecting each of the more than 400 quests in the system to academic standards. Third, QA uses an online, metagame strategy to establish a rich environment that sets up a meaningful context of participation. This strategy makes use of design features and strategies similar to those found in the more popular computer-based gaming environments to capture the interest of children. However, QA goes beyond the computer domain to engage children in their surrounding real community. Fourth, QA employs 3-D technologies to create an immersive experience and to support real-time collaborations, thereby engaging children (including girls and underrepresented groups) and teachers in the use of advanced technologies in a manner that organizes educational content, and does so in a context that may further engage children in undertaking intrinsically motivating challenges.

Fifth, the QA project has an explicit focus on engaging girls, a population that too often has been ignored or overlooked in the design of computer-based environments. QA has many features that focus on girls, including the incorporation of narrative and characters, multiple female role models, the use of guilds to support solidarity, the ability to collect objects, and the facility to customize avatars. Sixth, QA offers a flexibly adaptive curriculum, thereby supporting local adaptation and allowing each participating site to customize the experience in a way that meets its local needs. Seventh is the multidisciplinary focus, with QA being a metacontext that brings together content from multiple domains including science, math, reading, social studies, and language arts. QA contains multiple worlds, each dedicated to a particular theme and disciplinary content. For example, EcoWorld contains quests related to measuring water quality, understanding different habitats and biodiversity, practicing scientific inquiry, and many other topics related to ecology and the environment. This multidisciplinary content focus of the project allows for the broad-scale integration of QA in elementary schools. Lastly, QA does not simply involve working on the computer; instead it targets building connections, with most quests requiring that participants leave the computer and gather real-world evidence, thus helping to establish connections among children, parents, schools, after-school centers, families, and communities.

QA continues to change in terms of its technical structures and is continually retranslated in terms of its local contextualization by individual teachers. In this way, implementation is not a one-to-one mapping or rubber stamping of the designed environment to the new context. Instead, future users must always adapt the design for their local use, and this adaptation occurs as part of a larger institutional context. Successful designs are never placed in a black box, but instead are continually reinterpreted as part of the cultural systems in which they are being realized (Barab \& Luehmann, 2003). Scaling up educational initiatives involves careful attention to the cultural and social process in a given context-while being based on an effective program. It involves listening, respecting, and adapting to local concerns. QA has been successfully implemented in multiple contexts, including elementary schools and after-school centers, suggesting we have taken steps in the right direction. 


\section{IMPLICATIONS}

New technologies, especially the Internet, offer much potential as vehicles for intercultural collaborative inquiry, allowing us to develop global perspectives on local issues and to find complex approaches to complex problems. However, technology is only a tool-and one that is only as powerful as we choose to make it. Better understanding the value of this tool to support learning is a central concern and priority in our work. Further regarding the technology or, in this case, set of technologies as only one part of the overall activity structure has been a core evolution in our thinking throughout this project. We now see ourselves in the business of supporting the emergence of sociotechnical structures so as to support a common intersubjective experience, not simply designing technical artifacts. We have had to identify the core aspects of our vision and then determine what types of resources (situated potentials) would best engender the local productions of the pedagogical and social commitments that underlie our work.

It is our hope that through this project, children can learn from other cultures in a manner that will allow each one of us to grow as individuals, as responsible citizens, as loving members of the human family, and as considerate stewards of the earth. It is also our hope that through participation in QA, members will come to value their own communities and recognize not only that their communities value them but that they have important ways to contribute to their communities and the world. Projects such as QA, that value diverse perspectives, foster multicultural appreciation, and engage users in distance-mediated collaborations, bear much promise and responsibility. It is our hope that designers more generally will take up the challenge of socially responsive design, bringing a deliberate social agenda to their work.

Our approach to developing a design that sits at the intersection of entertainment, education, and our social commitments has evolved, and will continue to evolve as QA scales out, balancing tensions in ways that do not cater to any extreme yet do justice to all concerned. More generally, we have tried to leverage the motiva- tional value of games, offering children a safe and meaningful space for play while at the same time supporting autonomy, agency, collaboration, a sense of purpose and consequentiality, and even academic learning. Given that children's play spaces have been constrained from several square miles to, in some cases, a mere electronic screen-and moreover, given the potential consequences of this shift in children's activities-it is imperative that they be provided with the means for safe and productive play. We present this instance of socially responsive design work as one example of taking up this challenge. We look forward to reading more from our colleagues on the impact of this work on their thinking, on related work that they are carrying out, and on how we in the field of instructional design can best be of service to those for (and with) whom we design.

Sasha Barab [sbarab@indiana.edu] is at the School of Education, Indiana University, Bloomington. Tyler Dodge, Robert Carteaux, and Hakan Tuzun are with Instructional Systems Technology, at Indiana University. Michael Thomas is with the Department of Educational Psychology at Oklahoma University. Correspondence about the article should be addressed to Sasha A. Barab, School of Education, Room 2232, 201 N. Rose Ave, Bloomington, IN, 47405.

This research was supported in part by a CAREER Grant from the National Science Foundation, REC-9980081 and by the National Science Foundation Grant \#0092831.

\section{REFERENCES}

American Association for the Advancement of Science. (1993). Benchmarks for science literacy. NY: Oxford University Press.

Axelsson, A., \& Regan, T. (2002, January 29). How belonging to an online group affects social behavior: A case study of Asheron's Call. [Homepage of The Microsoft Research Publications]. Retrieved May 2, 2002 from the World Wide Web: http://research .microsoft.com/scripts/pubs/view.asp?TR_ID=M SR-TR-2002-07

Barab, S. A., Dodge, T., Jackson, C., \& Arici, A. (2003). Technical report on Quest Atlantis, Volume I. Bloomington, IN: Center for Research on Learning and Technology.

Barab, S. A., \& Duffy, T. (2000). From practice fields to communities of practice. In D. Jonassen, \& S. M. Land. (Eds.), Theoretical Foundations of Learning Environments (pp. 25-56). Mahwah, NJ: Lawrence 
Erlbaum Associates.

Barab, S. A., Hay, K. E., Barnett, M. G., \& Squire, K. (2001). Constructing virtual worlds: Tracing the historical development of learner practices/understandings. Cognition and Instruction, 19(1), 47-94.

Barab, S. A., \& Luehmann, A. L. (2003). Building sustainable science curriculum: Acknowledging and accommodating local adaptation. Science Education, 87(4), 454-467.

Barab, S., MaKinster, J. G., Moore, J., Cunningham, D., \& the ILF Design Team. (2001). Designing and building an online community: The struggle to support sociability in the Inquiry Learning Forum. Educational Technology Research and Development, 49(4), 7196.

Barab, S., Schatz, S., \& Scheckler, R. (in press). Using activity theory to conceptualize online community and using online community to conceptualize activity theory. Accepted in Mind, Culture and Activity.

Barab, S. A., Thomas, M. K., Dodge, T., Squire, K., \& Newell, M. (in press). Critical Design Ethnography: Designing for change. To appear in Anthropology and Education Quarterly.

Barab, S. A., Thomas, M. K., Dodge, T., Carteaux, R., Goodirch, T., Tuzun, H., \& Misanchuk, M. (2002). Quest Atlantis: Creating a community-based, online, meta-game for learning (pp. 235-243). Conference Proceedings of the International Conference of the Learning Sciences.

Bartle, R. (1996). Hearts, clubs, diamonds, spades: Players who suit MUDs. Retrieved July 30, 2002, from the World Wide Web: http://www.mud.co.uk/richard/hcds.htm

Bers, M. (2001). Identity construction environments: Developing personal and moral values through the design of a virtual city. The Journal of the Learning Sciences, 10(4), 365-415.

Bransford, J. D., Brown, A. L., \& Cocking, R. R. (Eds). (2002). How people learn: Brain, mind, experience, and school. Washington, DC: National Academy Press.

Brown, A. L. (1992). Design experiments: Theoretical and methodological challenges in creating complex interventions in classroom settings. The Journal of the Learning Sciences, 2(2), 141-178.

Bruckman, A. (1998). Finding one's own in cyberspace. In High Wired: On the Design, Use, and Theory of Educational MOOs. Ed. Cynthia Haynes and Jan Rune Holmevik. Ann Arbor, MI: U of Michigan P, 1998. 15-24.

Cassell, J., \& Jenkins, H. (1998). Chess for Girls? Feminism and computer games. In J. Cassell \& H. Jenkins (Eds.), From Barbie to Mortal Kombat: Gender and computer games (pp. 2-45). Cambridge, MA: MIT Press.

Castronova, E. (2001). Virtual worlds: A first-hand account of market and society on the cyberian frontier. CESifo Working Paper Series No. 618. Center for Economic Studies and Institute for Economic Research, California State Univ., Fullerton, December 2001.

Cole, M., \& Engeström, Y. (1993). A cultural-historical approach to distributed cognition. In G. Salomon (Ed.), Distributed cognitions. New York: Cambridge University Press.

Collins, A. (1992). Toward a Design Science of Education. In E. Scanlon \& T. O'Shea (Eds.), Proceedings of the NATO advanced research workshop on new directions in advanced educational technology. (pp. 15-22). Berlin: Springer.

Cordova, D. I., \& Lepper, M. R. (1996). Intrinsic motivation and the process of learning: Beneficial effects of contextualization, personalization, and choice. Journal of Educational Psychology, 88, 715-730.

Damar, B. (1998). Avatars! Exploring and building virtual worlds on the Internet. Berkeley, CA: Peachpit Press.

Dede, C., \& Ketelhut, D. (2003, April). Designing for motivation and usability in a Web-based multi-user virtual environment. Paper presented at the Annual Meeting of the American Educational Research Association. Chicago, Il.

Delgado-Gaitan, C., \& Trueba, H. (1991). Crossing cultural borders. New York, NY: The Falmer Press.

Dewey, J. (1938). Experience and Education. New York: The Macmillan Publishing Company.

Dick, W., \& Cary, L. (1990), The Systematic Design of Instruction, Third Edition, Harper Collins.

Donath, J. (1999) Identity and deception in the virtual community. In M. A. Smith \& P. Kollack (Eds.) Communities in Cyberspace. London; New York: Routledge.

Duffy, T. M., \& Cunningham, D. J. (1996). Constructivism: Implications for the design and delivery of instruction. In D. J. Jonassen (Ed.), Handbook of research for educational communication and technology (pp. 170-198). New York: McMillan.

Edelson, D. C. (2002). Design research: What we learn when we engage in design. Journal of the Learning Sciences, 11(1), 105-121.

Eden, C., \& Huxham, C. (1996). Action research for the study of organizations. In S. Clegg, C. Hardy, W. Nord (Eds.), Handbook of organizational studies. Thousand Oaks, CA: Sage. (pp. 526-542).

Engeström, Y. (1987). Learning by expanding: An activity-theoretical approach to developmental research. Helsinki, Finland: Orienta-Konultit.

Fine, M. (1996). (Eds.). Disruptive voices: The possibilities offeminist research. Ann Arbor, MI. The University of Michigan Press.

Finn, J. (1994). The promise of participatory research. Journal of Progressive Human Services, 5 (2), 25-42.

Freire, P. (1970/2000) Pedagogy of the oppressed. New York, NY: Continuum.

Fullan, M. (1993). Change forces: Probing the depths of educational reform. Bristol, PA: Falmer Press.

Gaver, W. W. (1996). Situating Action II: Affordances for interaction: The social is material for design. Ecological Psychology, 8(2), 111-129.

Geertz, C. (1976). From the native's point of view: On the nature of anthropological understanding. In K. Basso \& H. A. Selby (Eds.) Meaning in anthropology. Albuquerque, N.M: U. of New Mexico Press. 
Glesne, C. (1999). Becoming qualitative researchers: An introduction (Second Edition ed.). New York, NY.: Longman.

Grills, S. (1998). Doing ethnographic research: Field settings. Thousand Oaks, CA: Sage.

Heinich, R., Molenda, M., Russell, J. D., \& Smaldino, S. E. (1996). Instructional media and technologies for learning (5th ed.). Upper Saddle River, NJ: Merrill.

Herz, J. C. (1997). Joystick nation: How videogames ate our quarters, won our hearts, and rewired our minds. Boston: Little, Brown and Company.

Jenkins, H. (1998). Voices from the combat zone: Game girls talk back. In J. Cassell \& Jenkins, (Ed.), From Barbie to Mortal Combat: Gender and computer games. Cambridge, MA: MIT Press.

Katz, J. (2000). Up, up, down, down. Slashdot.org. Originally published November, 30, 2000. (http://slashdot.org/features/00/11/27/1648231. shtml)

Kolb, D. A. (1984). Experiential learning: Experience as the source of learning and development. Englewood Cliffs, NJ: Prentice Hall Press.

Kolbert, E. (2001). Pimps and Dragons: How an online world survived a social breakdown. The New Yorker, May 28, 2001.

Kollock, P., \& Smith, M. (1996). Managing the virtual commons: Cooperation and conflict in computer communities. In S. Herring (Ed.), Computer-Mediated Communication: Linguistic, Social, and Cross-Cultural Perspectives. Amsterdam: John Benjamins.

Koster, R., et al (2000). The laws of online world design, http://www.legendmud.org/raph/ gaming/.

Krajcik, J., Blumenfeld, P., Marx,, R. W., \& Soloway, E. (1994). A collaborative model for helping science teachers learn project-based instruction. Elementary School Journal, 94(5), 483-498.

Laurel, B. (2001). Utopian entrepreneur. Cambridge, MA: MIT Press.

Laurel, B. (2002, January). Gender and technology: A case study in design research and ethics. Presentation at Indiana University, Bloomington.

Levinson, B. (1998). The social commitment of the educational ethnographer: Notes on fieldwork in Mexico and the field of work in the United States. In Being reflexive in critical educational and social research. Geoffrey Shacklock and John Smyth, (eds.). London: Falmer Press. 83-109.

McLellan, H. (1996). Virtual realities. In D. Jonassen (Ed.) Handbook of research for educational communications and technology (pp. 457-487). Boston, MA: Kluwer-Nijhoff Publishing.

McNiff, J. (1995). Action research principles and practice. New York, NY: Routledge.

National Research Council. (1999). Designing mathematics or science curriculum programs: A guide for using mathematics and science education standards. Washington, DC. National Academy Press.

Poole, S. (2000). Trigger happy: Videogames and the entertainment revolution. London: 4th Estate.
Preece, J. (2000). Online communities: Designing usability, supporting sociability. Chichester, UK: John Wiley \& Sons.

Prensky, M. (2000). Digital game-based learning. New York: McGraw Hill.

Provenzo, E. F. (1991). Video kids: Making sense of Nintendo. Cambridge, MA: Harvard.

Provenzo, E. F. (1992). What do video games teach? Education Digest, 58(4), 56-58.

Randi, J., \& Corno, L. (1997). Teachers as innovators. In B. J. Biddle, T. L. Good, \& I. F. Goodson (Eds.) The international handbook of teachers and teaching (Vol.II, pp. 1163-1221). Dordrecht, The Netherlands: Kluwer.

Reason, P. (1994). Three approaches to participative inquiry. In N. Denzin \& Y. Lincoln (Eds.) The Handbook of Qualitative Research. (pp. 324-339). Thousand Oaks: Sage Publications.

Reid, E. (1999). Hierarchy and power. In M. Smith \& P. Kollock, (Eds.), Communities in cyberspace (pp. 107133). New York, NY: Routledge Press.

Reigeluth, C. M. (Ed.) (1999). Instructional-Design Theories and Models, Volume II: A New Paradigm of Instructional Theory. Mahwah, NJ: Lawrence Erlbaum Assoc.

Rogers, E. (1995). Diffusion of innovations (4th ed.). New York: The Free Press.

Rogoff, B. (1990). Apprenticeship in thinking. New York: Oxford University Press.

Roth, W.-M. (1998). Designing communities. Dordrecht: Kluwer Academic Publishers.

Schuler, D., \& Namioka, A. (Eds.). (1993). Participatory design: Principles and practices. Hillsdale, New Jersey: Lawrence Erlbaum Associates.

Schwartz, D., Lin, X., Brophy, S, \& Bransford, J. (1999). Toward the development of flexiblity adaptive instructional design. In C. Reigeluth (Ed.), Instructional-design Theories and models: A new paradigm of instructional theory (Vol II, pp. 183-214). Lawrence Erlbaum: Mahwah, New Jersey.

Schwen, T. M., Godrum, D. A., \& Dorsey, L. T. (1993). On the design of an Enriched Learning and Information Environment (ELIE). Educational Technology, 33(11), 5-9.

Scriven, M. S. (1983). Evaluation methodologies. In G. F. Madaus, M. S. Scriven., and D. L. Stufflebeam (Eds.) Evaluation models: Viewpoints on educational and human services evaluation (pp. 229-260). Boston, MA: Kluwer-Nijhoff Publishing.

Squire, K. (2002). Cultural framing of computer/video games. The International Journal of Computer Game Research, 2(1), Game Studies Available online: http: / / www.gamestudies.org/0102/squire / Retrieved 12-24-02.

Stake, R. E. (1978). The case study method in social inquiry. Educational Researcher, 7(1), 5-8.

Stake, R. E. (1995). The art of case study research. Thousand Oaks, CA.: Sage.

Stringer, E. T. (1996). Action research: A handbook for practitioners. Thousand Oaks, CA: Sage. 
Turkle, S. (1994). Constructions and reconstructions of self in virtual reality: Playing in the MUDs. Mind, Culture, and Activity 1 (3), 158-167.

Turkle, S. (1995). Life on the screen: Identity in the age of the Internet. New York: Simon \& Schuster.

Turkle, S., Dennis, P. D., et al. (2000/2002). Tech savvy: Educating girls in the new computer age. In E. Bucy (Ed.), Living in the information age: A new media reader (pp. 262-268). Belmont, CA: Wadsworth. (Reprinted report from 2000, Washington, DC: American Association of University Women Educational Foundation)

Vygotsky, L. (1933/1978). Mind in society: The development of higher psychological processes. Cambridge, MA: Harvard University Press.

Vygotsky, L. S. (1934/1986). Thought and language (A. Kozulin, Trans.). Cambridge, MA: MIT Press.
Wasson, C. (2000). Ethnography in the field of design. Human Organization, 59(4), 377-388.

Wells, G. (1999). Dialogic inquiry: Towards a sociocultural practice and theory of education.

Wertsch, J. (1985). Vygotsky and the social information of mind. Cambridge MA: Harvard University Press.

Wiggins, G. (1992). Creating tests worth taking. Educational Leadership, 49(8), 26-33.

Willet, R. (2001). Children's use of popular media in their creative writing. Unpublished dissertation, London: University of London, Institute of Education.

Women's Foundation of Colorado. (1999). Cyberpink: Are software companies selling our girls short? Denver: Women's Foundation of Colorado. Retrieved November 19, 2003, from http://www.wfco.org/ pdf/Research\%20\&\%20Publications/Cyberpink\% 20Report.pdf

\section{Leadership \& Technology International Convention}

Orlando, Florida

October 18-22, 2005

Teachers, Students and Technologies Coming Together www.aect.org 
Copyright of Educational Technology Research \& Development is the property of Association for Educational Communications \& Technology and its content may not be copied or emailed to multiple sites or posted to a listserv without the copyright holder's express written permission. However, users may print, download, or email articles for individual use. 